\title{
"Otherwise it would be nothing but cruises": exploring the subjective benefits of working beyond 65
}

\author{
By Frances Reynolds*, Alexandra Farrow* E Alison BlanK $^{*}$
}

\begin{abstract}
The age at which statutory and private pensions are being paid is increasing in many countries and hence more people will need to work into their late $60 \mathrm{~s}$ and beyond. At present, relatively little is known about the meanings of work for people who actively choose to work into their later life. This qualitative study examined the subjective benefits of continuing in a paid job or self-employment beyond the age of 65 in the United Kingdom. Thirty-one participants were interviewed, aged 65-91 years (median age 71), with 11 females and 20 males. Fourteen were working full-time and seventeen part-time. Interview transcripts were subject to thematic analysis. Although financial reward was acknowledged (more so by the female participants and the males who had young second families), there was more elaboration of the role of work in maintaining health and enabling continuing personal development. Work was framed as increasing personal control over later life, lifestyle choices and active participation in wider society, an antithesis to "cruising".
\end{abstract}

* Frances Reynolds, Alexandra Farrow and Alison Blank, Brunel University, Uxbridge, UK 
International Journal of Ageing and Later Life

Keywords: employment, older adults, health, well-being, personal development, qualitative.

\section{Introduction}

Older people appear to derive positive well-being from a range of activities, including recreational interests, contributing to others and achieving valued goals (Henricksen \& Stephens 2010; Hinterlong et al. 2007). The meanings of continuing paid work or self-employment in later life deserves more research attention, particularly as the default retirement age has been or is being abandoned in many countries, with consequent delays to payment of both statutory and private pensions. These political and economic changes are likely to lead to an increasing number of older people remaining in (or returning to) work. This qualitative study examined the subjective benefits of continuing in a paid job or self-employment beyond the age of 65 in Britain. Data were collected a few months prior to the abolition of the default retirement age in October 2011.

In Britain, individuals are eligible for a state pension if they have made contributions to the National Insurance (NI) scheme over a 30 year period of employment. Until recently, women received state pensions at 60 years and men at 65 years, but currently women's age of entitlement is being raised. By the year 2018, both men and women will become eligible at 65 years. This will rise to 66 years in 2020. According to a recent Pensions Policy Institute (PPI) report, $61 \%$ of retired people in the United Kingdom also receive occupational pensions, but this leaves a large minority reliant solely on the state pension, additional state benefits and personal savings (PPI 2011).

Even before the British government abolished the default retirement age, an increasing proportion of people were working beyond statutory pension (SPA). In 2011, there were about 1.4 million such workers (Office for National Statistics; ONS 2012), with higher proportions working in the more affluent South East regions of the country. Self-employment is more common among people working beyond SPA, with $32 \%$ in this category, compared with $13 \%$ of younger workers. This post-SPA workforce is also more likely to be working part-time (66\% compared with $25 \%$ of people under SPA). Working patterns are different for men and women, with men 
in highly skilled jobs (and women in lower skilled jobs) more likely to work beyond SPA. These patterns suggest that men may be motivated more by interest in their work, whereas women may work primarily for income. Women are more vulnerable to poverty in later life (about 52\% received less than the full state pension in 2010 through not having paid the required set of NI contributions) and, hence, may need to continue working for financial reasons. As with the wider British population, relatively few older people work in the manufacturing sector (Hotopp 2005). Disney and Hawkes (2003) have argued that the growth of the service sector, with its more flexible hours and less physically demanding work, has helped facilitate the rise in later life working over the past two decades.

Previous research on people's reasons for working beyond SPA is somewhat limited (Kooij et al. 2007). Studies that have examined attitudes to later life working have tended to focus on "older workers" who are in their 50s and approaching statutory pension age (SPA) rather than focusing entirely on the views of those who are currently working beyond 65 (e.g. Felstead 2010; Shacklock et al. 2009; Templer et al. 2010). Attitudes to work among people who are approaching retirement age may differ from those who have actively chosen to work beyond this age.

Financial need and work satisfaction (or fulfilment) have been noted in several studies as key motivators for working beyond SPA (Barnes et al. 2004; Smeaton \& McKay 2003; Smyer \& Pitt-Catsouphes 2007; Templer et al. 2010). Choi (2001) found that the life satisfaction of women working into later life was more dependent on their financial resources and feelings of economic security than the work itself. However, Humphrey and colleagues (2003) reported that participants remaining in work between 65 and 69 years did not give high priority to financial needs. In contrast, Smeaton and colleagues (2009) surveyed older workers about their decisions to continue working or retire at SPA. Perhaps reflecting worsening economic conditions since the earlier studies, the authors found that financial motives predominated in the decision to work beyond SPA. Nonetheless, certain psychological needs were also uncovered. As in previous studies, many people continued to work because they enjoyed the content of their work and using their job-related skills. They also wished to preserve routine and keep busy, make a worthwhile contribution and enjoy social contact. Those who had better education aimed to work for 
International Journal of Ageing and Later Life

longer, and about $10 \%$ of the men surveyed wished to set up their own business after SPA. Nonetheless, the majority who were planning to stay in work wanted to reduce their hours to gain a better lifestyle balance. In this study, the "push" factors encouraging older people to leave work at or before SPA included stress at work, long commuting journeys and tiredness.

Phillipson and Smith (2005) noted that people are more likely to work in later life if their partners are working, if they have outstanding mortgage debt and if they enjoy better education and higher status work. McNair (2006) reported similar findings. Komp and colleagues (2010) also found across Europe that people who remained in work from 60 to 70 years of age tended to have more education and more prestigious jobs. As a group, women may have greater financial needs than men (and thereby feel more obliged to work beyond SPA) because they have more limited pension entitlements linked with career breaks, and their greater likelihood of working for large parts of their adult life in part-time and/or lower paid jobs (Phillipson \& Smith 2005; Templer et al. 2010).

The decision to work beyond SPA is also shaped by people's attitudes to work, and degree of identification with their working roles (Barnes \& Parry 2004; Barnes et al. 2004; Parry \& Taylor 2007). It has been suggested that even though women commonly have poorer pension entitlements, older men are more likely to delay retirement through being more attached to their worker identities and through having insufficient time or inclination to acquire alternative satisfying roles and activities during their earlier working lives (Barnes \& Parry 2004).

Barnes and colleagues (2004) and Parry and Taylor (2007) reported a qualitative interview study that was unusual in identifying distinctive motivations for working among different groups of people working beyond statutory pension age. Data were gathered from 24 interviewees (21 of whom were over 60, with 17 continuing to work beyond SPA) and additional focus groups. Work was valued for promoting personal and social identity. One distinct sub-group of participants, labelled "workers", identified themselves as people who had always worked hard and who enjoyed being active and "doing". These older workers did not necessarily gain deep satisfaction from their work roles but some continued to work through fearing that retirement would bring inactivity which risked 
turning them "into a vegetable" (Barnes et al. 2004: 32). Many from this group also needed extra income to supplement their limited state pension. In contrast, intrinsic motivations for working were typically emphasized by those involved in professional or creative roles. These participants resisted retiring at the SPA because they enjoyed autonomy, creativity and deep satisfaction at work. The third group consisted largely of selfemployed entrepreneurs who emphasized that their work offered selfdirection and self-sufficiency. Some who owned their own businesses enjoyed continuing (or having even more time) to work with their spouse or partner. The importance of paid work for confirming personal identity and for offering social contact has also been found in other studies of older workers (Aquino et al. 1996; Noonan 2005). However, various discomforts in later life working have also emerged, including experiences of regret about limited personal development, insecurity and age discrimination (Altschuler 2004; Noonan 2005).

In conclusion, previous studies have found that the decision to work beyond statutory pension age is often driven not only by financial concerns, but also a complex array of psychosocial needs. Later life working may help some people to maintain a familiar positive identity, larger social networks and a suitable balance of activities both with and without their partners. However, the potential of work to promote older people's generativity or personal development has been relatively neglected. Given changing economic conditions, recent legislation to delay SPA, and the likelihood that increasing numbers of people will be working into their late $60 \mathrm{~s}$ and beyond, further enquiry into people's experiences of working beyond 65 is justified. Even though some large-scale surveys are available (e.g. Komp et al. 2010), a qualitative research method is highly suitable for eliciting nuanced accounts of the meanings of work, with potential for uncovering some new issues.

\section{Method}

\section{Ethics}

Prior to data collection, the project was approved by the ethics committee of the host university. Participants making enquiries about the project 
International Journal of Ageing and Later Life

received full information, including the interview topic guide, and signed consent forms prior to interview. In line with ethics committee requirements, all data have been anonymised and are held securely. Participants are referred to by pseudonyms.

\section{Design}

A qualitative interview study was conducted based on single interviews with people working at or beyond 65 years of age. Participants were eligible to join the study, if they were in full-time or part-time paid employment or self-employment. There were no further criteria.

\section{Recruitment}

Participants were recruited through local and national advertising in the United Kingdom. Full information was sent to those who expressed interest in the study.

\section{Sample}

The sample comprised 31 people aged 65 or over who volunteered within the required time frame. Participants were aged between 65 and 91 years (11 women, aged 65-76; 20 men, aged 67-91), and all were in paid employment (18) or self-employment (13) at the time of interview, with a median age of 71 years. Fourteen were in full-time work, mostly males (12 males; 2 females) and seventeen worked part-time (9 females and 12 males). Twelve people (7 females; 5 males) had previously worked or were continuing in the public sector (in education and health services), and most of these had opted for part-time hours. Various types of work in the private sector were also described, with individuals engaged in market research, estate agency, company management, tax consultancy, creative writing and horticulture. Most of the sample had persisted with their main careers, either full-time or moving to part-time hours. Two women and five men had changed their lines of work after retiring from their main careers (e.g. developing a mail order business after retiring from a health profession; working with asylum seekers within the judicial system after a career in education). 
Exploring the subjective benefits of working beyond 65

\section{Procedure}

Semi-structured interviews were conducted in person or by telephone, according to participants' preference. All interviews were audio-recorded and transcribed verbatim. Interviews were on average one hour in length, with face-to-face and telephone interviews being similar in duration and richness of data. The key topics were presented to participants (along with the information sheet), with additional questions asked in the interview as needed to help them elaborate their accounts:

1. A brief overview of the participant's past and current work.

2. The perceived benefits of working beyond what many regard as the "expected" age of retirement.

\section{Data analysis}

This report is based on a thematic analysis of the data (Braun \& Clarke 1996). Independent coding by the researchers, and discussion to elaborate emerging interpretations of the data, helped to establish the credibility and trustworthiness of the findings.

\section{Findings}

In the following quotations, intentional shortening is indicated by the usual convention for ellipsis (...). Words that have been added by the authors to clarify the meaning of quotations are indicated by square brackets.

Three main themes emerged, namely that later life working was valued for increasing financial security, that it helped to maintain health and that it offered many opportunities for continuing personal development. Overall, most participants regarded later life as a time for continuing active participation in their wider social networks and perceived their work as supporting this endeavour. Linguistically, these attitudes were conveyed by the recurring strategy of comparing the self more favourably to others who had decided to retire and by using negative descriptors such as "lazy", "cruising" or "dull" to depict a retired lifestyle characterized by lack of 
International Journal of Ageing and Later Life

direction and personal effort. These issues will be commented on during the presentation of themes below (Table 1).

\section{Financial security}

As in previous studies, and unsurprisingly, working beyond 65 was valued by some for increasing income. However, just over half of the participants did not refer explicitly to this issue. Two principal reasons were put forward for needing to supplement pensions, namely to support a more varied, satisfying lifestyle and to support other family members.

a. Maintaining a satisfying lifestyle. Some of the female participants described how they would struggle to survive on a basic state pension and, therefore, felt obliged to continue in work. They had contributed little or nothing to occupational pension schemes through having had disjointed work histories or poorly paid jobs for much of their working lives. Aileen (aged 67 years and working in a telephone call centre) summed up her reasons for working as "lack of a pension mainly". Even so, income was rarely an end in itself. Rather, the income earned through working enabled participants to participate in more activities than would be possible on a basic state pension. Aileen went on to explain:

Table 1. Interview themes: subjective benefits of working beyond 65

1. Financial security

a. Maintaining a satisfying lifestyle

b. On-going support of dependents

2. Active control over health

a. Keeping physically active

b. Mental alertness and vitality

c. Work obligations and routines help resist "giving in" to illness, laziness and low mood

d. Work as a distraction from pain and other health problems

3. Later life as a time for continuing personal development
a. Learning and change
b. Challenge and achievement
c. Social connectedness and affirmation
d. Resistance to ageist stereotypes
e. Preserving personal and professional identity 
Exploring the subjective benefits of working beyond 65

The job allows me to do the sort of things I enjoy doing [like] travelling to meet my family.

Having a higher income than afforded by a basic retirement pension was perceived as enabling a more varied lifestyle, which in turn was thought to promote emotional and physical health:

Well, I think it [work] just keeps your mind active and, uh, well a lot of it's the money that it gives you ... I mean I like to swim and I like to play bowls and I like to play tennis ... We're going to Egypt, and I'm going to Holland next week ... The work pays for you to do all these things. Although you get a pension, it's not a brilliant pension at the minute.

(Sarah, 68, "bank" nurse)

A few were using some of their increased income to fulfil long-held plans:

If I had the money [when younger], I'd have learned to fly, but then I'm now too old and I've got a pacemaker, so that's not going to happen, but I have to confess, I bought a flight simulator a month ago, a computer programme!

(James, 79, set up a successful mail order business after retiring from his main career as a social worker)

b. On-going support of dependents. Several participants needed additional income not only for maintaining their personal lifestyles but also for supporting others within their families. Four male participants were supporting dependent children, through having second families with much younger wives:

Having a $12^{1 / 2}$ year old daughter, I'm compelled to do quite a lot of things, which I would not necessarily do, to support her, but I find very rewarding.

(James, 79, also quoted in the previous section).

Some of the other participants (both male and female) also referred to their need or wish to support adult children who were in financial difficulties, for example, through being unwell or recently divorced.

And the money is handy because we have a daughter living in America who's a ... transplant patient. And, um, her health is indeterminate. You know she's reasonably well, but we're able to help her financially because I work ... Earlier in the year, 
International Journal of Ageing and Later Life

she had pneumonia and she had to get some inhalers and they weren't covered by the medical insurance, so we had to pay for the inhalers.

(Marilyn, 69, nursery school administrator)

Although a sizeable minority included a financial motive among their varied reasons for continuing to work, several participants rejected this motive entirely:

I like being away from the house (pause) I do like a mixture of people ... It sounds as though we're incredibly rich but we don't need the money. I have the mortgage paid and my husband gets a reasonable pension, so it's not about the money. (Jennifer, 65, market research interviewer)

\section{Active control over health}

a. Keeping physically active. Physically, most of the participants regarded themselves as in at least reasonably good health and, therefore, capable of work. Many links were made between keeping physically active through work and other activities, and staying fit:

I'm not slowing down at all, in fact, to the contrary because I had about five or six years when I had a health problem and in fact, I thought I'd have to give up [work] because of that, but I managed to get through it and it was treated. So since I've really recovered from that, I feel a new lease of life, so I feel better in myself than eight years ago.

(Marta, 71, executive coach)

Almost all participants regarded their continuing work as promoting or maintaining their physical, as well as mental, health.

I don't feel inside, old. And I think that that is encouraged by continuing to work. And it's probably the biggest ... one of the biggest contributory factor to what follows from that, which is basically, reasonably good health.

(James, 79, mail order business owner)

Many participants defended their arguments about the health benefits that they attributed to working by contrasting their own good health with that of others whose retirement was shortly followed by illness: 
I always feel sorry for people who retire at the age of whatever it might be, say 55, and they only last for a few weeks or a year or so and then they're dead ... and that can happen either because they've become vegetables and sort of not got up from their chair to turn the TV off or on ... or it can be because of the nature of the job they did. (Adrian, 72, part-time estate agent)

b. Mental alertness and vitality. Complex transactions were portrayed between physical and cognitive health. Most participants thought that their work benefited their overall health through encouraging mental engagement and preserving vitality:

I think one could quickly stagnate really, just not becoming involved ... it allows me to still explore quite new and exciting concepts and ways of working and in that way, I think it does keep me very alert ... When you have to do things, you're timetabled to do them and there's a sense of vitality almost, it's difficult to explain precisely, but I think that vitality, that awareness of things increases.

(Beatrice, 70, art therapist)

Some spoke of feeling refreshed, rejuvenated or younger since they had returned to work after retiring from their main careers:

The whole attitude that someone of my age, or my wife's age, has to working and to living, is [that it is] part of the rejuvenation process. For Saturdays [taking people on property viewings for an estate agency], I think, oh you know, I've got to be sort of bright and sharp ... and unconsciously that may sort of be an aid to maintaining good health.

(Adrian, 72, part-time estate agent)

Some who worked in part-time consultancy roles experienced periods of stagnation when not called upon to work, again confirming the sense of vitality that they drew from their valued occupation:

If I have long periods of inactivity, if we don't have much work on ... I do miss the buzz ... I'm saying that it [work] has kept me healthy.

(Laura, 73, self-employed in-service course instructor)

c. Work obligations and routines help resist "giving in" to illness, laziness and low mood. Work was valued for preserving vitality and health 
International Journal of Ageing and Later Life

partly through maintaining the person's engagement in healthful routines. Accounts implied a strong belief in exercising personal control over health.

I think if I didn't do it [work], I would just sag, I would let it [health] get worse. (Jeffrey, 88, freelance writer, living with long-term illness).

Many described making efforts not to "give in" to the threat of physical or mental deterioration and perceived their work obligations as helping them to resist illness:

If you're, say, doing a viewing of a house [in estate agency], you're doing a presentation, and you can't stop half way through and think ... oh I've got a headache or I've got this, I've got that. You drive things like that away.

(Adrian, 72, part-time estate agent)

There was a commonly expressed fear that giving up work would lead to both mental and physical "laziness", through disconnection from the stimulating experiences that maintained cognitive functioning. Again, it was a common linguistic strategy for participants to draw a contrast between their own engaged and busy lives and the lives of others who had retired:

\footnotetext{
Some of these guys [I knew] in the larger companies, they had this statutory retirement age of 65 or whatever, and the first six months, they're euphoric. And then after six months, irrespective of whatever hobbies they had, which they enjoyed anyway while they were at work, they became a bit ... not down but there wasn't a focus of getting up every morning. And that, I don't want. I'm up at five every morning. I check the [computer] screen, shower, I go to an office ... the last thing at night, probably go to bed at eleven, just check things [e-mails], do a bit of reading, that's it, that's basically the working day to be honest.

(Derek, 68, ship-broker)
}

d. Work as a distraction from pain and other health problems. The minority who described themselves as having health problems generally considered that they had adapted their working patterns to suit their decreased energy and functional levels. Several of this group valued their work as it distracted them from pain or other limitations.

I had this, couple of years ago, a very nasty operation. I had my right leg removed. That pinned me down very badly. I am in a wheelchair all the time, but I'm still going 
on, I'm just finishing a novel. Funny enough, in hospital, I corrected the proofs of $\mathrm{X}$ [a novel], which came out last year ... They [nurses] were very sweet, they brought me coffee and things, it kept me going and the book came out. It may not sound a lot nowadays, I'm not making very much [money] at all, but it keeps me going. I don't just sit here thinking what a miserable time I'm having.

(Jeffrey, 88, freelance writer)

The enjoyment, deep focusing or flow associated with work encouraged some to continue working despite their health problems, rather than accept retirement:

You know, because of my physical problems or health problems [prostate cancer], I think if I had not been working I would have worried about them much more. Of course working distracts you, because you have far more important things to do than be worrying about your twinges and the rest of it.

(Joseph, 78, self-employed recruitment consultant)

\section{Later life as a time for continuing personal development}

Most of the participants regarded their later life as a time for continuing change and personal development. Some had chosen to work part-time in order to have more opportunities to engage in new experiences such as travel and volunteering. But work was also seen as offering opportunities to develop skills and experience new challenges.

a. Learning and change. Continuing in work beyond 65 was perceived as promoting subjective well-being through offering a range of opportunities to learn, develop and to keep updated:

\footnotetext{
I have to say I watch them (other older business people) very closely because I look and I think "Well, I wouldn't have done that, you're doing that because you're old" ... People say "Well in my day, how we used to do it ..." You've got to beware of that, it's a different world now that we're in. [If people say], "It wouldn't be done like this when I first joined" or "Now, I've been here so many years and I can remember ..." Not interested! We haven't got time, we're moving on!

(Jack, 67, Director of Communications, manufacturing company)
}

Most of the participants (most typically working in the business, creative and health sectors) presented themselves as having a strong need for continuing problem-solving, new activities and personal development in 
International Journal of Ageing and Later Life

their lives. Some were motivated to keep up with rapidly changing evidence and technology, in order to remain stimulated and to see themselves as active players in both the work context and wider society.

The work is constantly stimulating, the internet world is a changing world. Yesterday, we spent all day in Earls Court [conference centre] looking at various things in the internet marketing side and ... there's a sort of circular stimulating ... you do some more and then you want to do even more.

(James, 79, self-employed mail order business).

Many participants described having a strong need for personal development in their earlier working lives, a need that prompted them to devise a post-retirement age "career", either by setting up a new business venture, or by constructing a "portfolio" of interesting part-time jobs.

If I didn't do this [job], I've got two or three other good business ideas, which would be equally interesting, though I see no point in retiring. I expect to have an interesting life where I can laugh a lot and think a lot and where my experience can be useful to people, where their experience can be useful to me.

(Adam, 75, business consultant)

In undertaking these new initiatives, being older was generally considered an advantage. Without mortgages to pay, and with the helpful "fall-back" of a State (and in some cases an occupational pension), several participants (mostly women) described taking on more training, and/or riskier projects that might not pay well, but that promised fulfilment in their work and personal growth.

b. Challenge and achievement. Work's challenges, achievements and excitements motivated the majority of the participants to continue, increasing subjective well-being:

It's still as exhilarating to get involved in dealings, quite frankly, so yeah, that's about it [the main reason for continuing in work].

(Derek, 68, ship broker)

Challenges were enjoyed for their own sake and for challenging (in self and others) any negative expectations of later life: 
I enjoy challenges, with the computer for example, because like most people of my age I came to computers late in life. And I still enjoy being able to, ooh, I can remember how to fix the heading on my Excel table that I've just set up to monitor the incoming voucher payments .... I think it gives me a purpose .... Plus I like using the skills I've acquired. And I like feeling youthful and I like the contact I have with the parents.

(Marilyn, 69, nursery school administrator)

Several described taking on new work roles in recent years which offered a level of challenge that they now felt better prepared for, through their increased age and experience:

I do a session with very challenging boys at a residential unit for teenage boys and that has also made me very aware of ways of working that perhaps I hadn't thought of before and it's quite a new area for me, but one that I'm finding very rewarding.

(Beatrice, 70, art therapist)

Despite their need for challenge, it should be noted that about half had taken up part-time work (or self-employment) in their 60s and described thereby gaining a more satisfying balance between challenge and relaxation in their lives.

c. Social connectedness and affirmation. There was a recurring emphasis on the ways in which work confirmed the person's sense of social value, maintaining self-esteem and (among those who worked with colleagues) offering a respected place within the team:

You need to feel properly engaged and valuable.

(Adam, 75, business consultant)

There are people there [at work] who regard me as an integral part of the team ... My boss always said that I was, you know, a valuable person ... She didn't ask my age. Because it didn't matter

(Adrian, 72, part-time estate agent)

Nearly every participant had social reasons for working, including many who were delighted in being more appreciated and less taken-for-granted by colleagues since moving to new work roles after retirement from their main careers. Some were surprised at the level of respect received from 
International Journal of Ageing and Later Life

colleagues and/or clients, which they connected with their considerable work experience and commitment to their roles:

I can get dragged in [by other vets in the practice] to look at X-rays time and again because when you've been looking at X-rays for 40 years, you see things that, no matter how highly qualified a youngster is, they just haven't been doing it that long. And I must admit, that is one of the rewarding parts of it, is somebody saying "Oh, could you have a look at this, Graham?"

(Graham, 68, locum vet)

Participants who essentially worked alone (usually in self-employed or freelance roles) also referred to the pleasure of gaining social contact and status from their work roles:

I don't make very much [money] now, but people still know me and improbably I was invited to a Convention ... in X [town] because I had written [this novel] ... and people are still in touch and that's a nice thing.

(Jeffrey, 88, freelance novelist)

Participants who lived alone also appreciated the social value of working:

It's nice to be acknowledged, isn't it, in the street? People know you, for whatever reason ... I would hate ... to sit back in my little flat just drinking gin or beer and not mixing with anybody, that's certainly a total disaster.

(Christopher, 70, part-time hospital worker; former engineer)

d. Resistance to ageist stereotypes. Some participants explicitly framed work as challenging the ageist stereotypes which they thought were prevalent in the wider culture. Beatrice, for example, had been obliged by the health authority to leave her full-time post at the default retirement age, and felt insulted by her colleagues' reactions:

People kept saying "Oh, are you going on cruises?" and all this sort of thing and if I met ex-colleagues, they'd raise their voices as if I might have instantly kind of developed general deafness or something (laughs) ... I found all that quite irritating.

(Beatrice, 70, art therapist) 
Doug (73) had taken up new part-time work as a family mediator within the court system after retiring from his main career. He was aware of ageist stereotypes:

People assume that if you retire you've kind of lost all of that [knowledge] or somehow ... didn't ever have those skills. I think some people feel like that.

For several participants, the prospect of spending their days in leisure activities such as golf and taking holiday cruises appeared to threaten their sense of self as an actively engaged, self-directed person:

I enjoy my work and I play at it in a serious sense, work is serious play for me, I think I'm very lucky in the sense that I've built my life around work ... there seems to be a view that the way to enjoy the rest of your life is to retire and stop working. I don't think I subscribe to that. I know people who spend their life on the golf course that, on the whole, are pretty dull, they are pretty dull.

(Adam, 75, manager)

e. Preserving personal and professional identity. Most of the participants described needing to work to confirm their personal or professional identities:

I think it [work] does give me a feeling of who I am.

(Marilyn, 69, nursery school administrator)

Some who had moved on from their original jobs nonetheless conveyed that their new roles provided them with a sense of personal and professional continuity. Graham, for example, was rather self-deprecating about his veterinary career and yet also conveyed some pride in what he was achieving in his current locum position:

I suppose in a way it's a bit sad but I think, to some extent, I'm defined by what I do. When I had the [veterinary] practice, which I sold, I was the town vet ... whereas now, I'm just a Joe standing behind a table [as a locum] but older people tend to say "Oh, is he there today?" because they like an older person. Which is quite interesting.

(Graham, 68, locum vet) 
International Journal of Ageing and Later Life

For many, particularly the male participants, work was much preferred to leisure pursuits that had never offered a positive source of identity:

I enjoy it [work], I suppose that's it, also I'm not interested in golf or those sorts of activities really, I've never been sporty.

(James, 79, self-employed mail order business)

Participants were asked during the interview if they had any plans to retire, to further elucidate the meanings of work. Few perceived any obstacles to continuing in their roles, unless ill-health (of self or partner) intervened.

I just think if you keep your mind active and you're doing something that you think is worthwhile and fair, then I don't see you should see an end really, I think you just should go on whilst you're still capable.

(Linda, 76, former teacher, now represents asylum seekers within the legal system, part-time)

The oldest participant (Bob, 91, part-time tax accountant) was on the brink of retiring only because his wife was seriously ill.

Some participants even revealed plans for new work-related activities should they retire from their current jobs, again confirming the powerful identity functions of later life working:

I think I probably would embark upon a course of study, teaching, if I weren't working, because I have done lots of different study and I still do because I'm a professional coach and I have to do continuous personal development. So I'm always doing things, I'm going on a course in a few weeks' time ... I think I would go into something more academic if I weren't working.

(Marta, 71, executive coach)

Almost all participants summarized their experience of later life working as preserving their identities or sense of self. Interestingly, four participants explicitly rejected the notion of "cruising" as a suitable retirement occupation, with its associations of passivity and over-indulgence:

I'm sure cruises are very nice, I haven't got anything against them, but it was the thought ... retired? You're into cruises and nothing meaningful in life ... I've enjoyed life outside being an art therapist, but nevertheless, whether you like it or not, it's 
become an integral part of your identity and there's a sense of mourning when one day you're there and the next day you're not.

(Beatrice, 70, art therapist)

Nonetheless, it is to be noted that just over half of the participants were working part-time. It appeared therefore that identity was maintained through exercising choice over the balance of lifestyle activities and preserving what they regarded as sufficient connection with their careers.

\section{Discussion}

The participants in this study almost all portrayed themselves as a highly engaged, experienced workforce, largely unencumbered by the frailties that can result from the ageing process. In this respect, they resembled post-SPA workers in previous studies whose good health is presented as enabling them to continue in the workplace (Barnes et al. 2004; Ozawa \& Lum 2005). Previous studies of people's motives for continuing in work up to and beyond the default retirement age have tended to focus on financial gain, work fulfilment, social contact and life satisfaction (Barnes et al. 2004; Feldman \& Kim 2000; Smeaton \& McKay 2003; Smyer \& Pitt-Catsouphes 2007; Warr et al. 2004). On the whole, these previous studies have portrayed good physical health primarily as a prerequisite for working beyond SPA not as a subjective benefit of continued employment. Positive health consequences of post-SPA working were noted by Barnes and colleagues (2004) but by very few participants. Some reviews and empirical studies of older people's reasons for working into their mid-60s and beyond have not uncovered any themes relating to health benefits (e.g. Feldman \& Kim 2000; Kooij et al. 2008; Templer et al. 2010). Yet this particular theme was prominent in the current study and is worthy of further exploration.

The routines and regular obligations of work were experienced as helping participants to preserve their current health status, experience more vitality, and in some cases, to recover from illness and to resist further deterioration. These subjective views resonate with research findings which link personal control beliefs to the maintenance of health in later life. For example, older people who have strong beliefs that they can influence their 
International Journal of Ageing and Later Life

own health show less cognitive decline over time (Caplan \& Schooler 2003), and seem to use more active health promotion strategies (Lachman 2006).

Previous studies have presented personally valued goals and projects as contributing to well-being in later life through enabling personal development, cognitive stimulation and social engagement, although they have mostly focused on recreational pursuits (Henricksen \& Stephens 2010; Howie 2007; Lampinen et al. 2006; Reynolds 2010). This study found that paid work and self-employment may have similar meanings for people who choose to continue working into their 70 s and beyond. The qualitative accounts revealed that work post-SPA held a rich array of meanings, and that participants were motivated not only by financial benefits, but also their needs for personal development, identity, stimulation, challenge, and a sense of belonging within a wider social network. The majority of the participants in this current project were explicit about the intrinsic wellbeing derived from maintaining their involvement in learning and taking on new challenges right into their seventh and eighth decade of life. These benefits are well described by the concept of flourishing. Keyes and Haidt (2003: 6) describe flourishing individuals as "truly living rather than merely existing" and as being filled with "emotional vitality", and these phrases very much reflect participants' accounts.

Participants also appeared to manifest many of the characteristics of "successful", "active" or "positive" ageing. These overlapping, multidimensional constructs encompass not only the experience of good physical health in later life but a state of life satisfaction derived from engagement in meaningful roles, personal development and affirmative social relationships (Hill 2006). The findings demonstrate that older people may be actively engaged in transforming the meanings of later life and what may have previously been regarded as normative leisure-focused lifestyles for this life stage (Westerhof \& Tulle 2007). Whilst there were proportionately a few more females who described themselves as working primarily for financial reasons (as expected from previous research), accounts were not otherwise strongly gendered (in some contrast with the findings of Barnes \& Parry 2004). The one exception was that a few of the male participants were living a lifestyle perhaps more "typical" of mid-life fathers, with young families for whom they were financially responsible. Most of the men and women who were interviewed framed 
their later years as a period of opportunity rather than decline, and a time to apply and further develop their work-related expertise rather than withdraw wholly into leisure and family activities. Only poor health (of self or partner) was seen as a significant future threat to continuing in work.

\section{Critical evaluation}

No simple generalizations are possible from qualitative studies, not least because participants are inevitably self-selected. By virtue of their interest in being interviewed, volunteer participants tend to be reflective and better educated. As in previous research (Barnes et al. 2004; Smeaton \& McKay 2003), very few reported manual employment, and no-one reported working in harsh conditions, so the experiences of people who continue to work post-SPA in physically challenging jobs through absolute financial necessity rather than through choice are largely absent from the data. Participants, especially the men, tended to have had professional and managerial careers, and potentially had considerable choice over both the nature and hours of their work post-65. Nonetheless, the sample should not be regarded as an "elite" group of post SPA workers as it was broadly reflective of wider national figures, especially in relation to post-SPA men who are more likely to be found in high-skills jobs, management and self-employment (ONS 2012).

Whilst the study identified a number of subjective benefits associated with continuing to work into later life, no objective benefits can be established (e.g. concerning physical or cognitive health). No comparison was made with retired people of similar age who may derive similar levels of well-being from engaging in leisure or volunteering activities (Warr et al. 2004) or from experiencing high levels of choice over other aspects of their lives (Herzog et al. 1991). Nevertheless, the participants' beliefs in the many health and subjective benefits of continuing to work beyond 65 clearly deserve further enquiry. Caution is needed, though, as such benefits will not necessarily be experienced in the future by older people who are obliged to work for longer through government decisions to increase SPA, rather than through their own choice.

Positively, the sample was larger, and older, than those recruited in most previous UK qualitative interview studies of people working beyond 
International Journal of Ageing and Later Life

statutory pension age (e.g. studies by Barnes et al. 2004 and Parry \& Taylor 2007 were based on 17 people working past SPA). It has been valuable, in particular, for illuminating the complex array of reasons why people choose to work into their 70s and beyond. Saturation in the themes offered credibility to the findings.

\section{Conclusions}

This qualitative study was based on the accounts of 31 men and women working in the UK context beyond 65, with a median sample age of 71 years. Just over half were working part-time; a small minority worked in manual or semi-skilled occupations, and therefore the group was reasonably reflective of the patterns seen in the wider population of people working post-SPA in the United Kingdom (ONS 2012). Thirteen were selfemployed and this also tallies broadly with the one third of this age group who are self-employed according to recent British figures (ONS 2012). Most $(77 \%)$ were continuing with their main careers (full-time or parttime), rather than entering bridging or low status roles, and this also matches broader population trends (66\% of people working beyond 65 in the United Kingdom have remained with their employers according to ONS 2012). The male sample had a high proportion of professionals in highly skilled jobs, but this is characteristic of the wider pattern noted among men working beyond SPA (ONS 2012).

Nearly half the sample appreciated the additional income gained by working, but this was never portrayed as the sole reason for continuing to work. Those who did emphasise the financial benefits of working desired additional income to pay for favoured leisure occupations, to assist adult children (or, in a few cases, to support young children in their second families) or to support their voluntary work (e.g. travel abroad). The sample included very few people who were working primarily to provide for fundamental everyday needs.

In this sample, the decision to continue in work beyond 65 reflected a complex array of reasons. Most of the men and women found enjoyment and satisfaction in the work itself, and believed that their work increased or maintained their health and well-being. These reported health-related benefits of later life working have been largely neglected 
in previous studies. Several used their late 60 s and beyond to set up businesses, or to develop part-time in roles that brought particular satisfaction, or challenges. One implication is that older people might gain a more satisfactory, as well as more affluent, lifestyle by planning for a similar balance of occupations post-SPA. Coupled with published evidence showing that engagement in committed activities such as volunteering and active leisure predicts greater longevity and cognitive health (e.g. Harris \& Thoresen 2005; Luoh \& Herzog 2002; Newson \& Kemps 2005; Scarmeas \& Stern 2003), a need for further longitudinal research into the health benefits of later-life working is indicated.

The majority of participants were self-employed (full- or part-time) or working for employers part-time. Both of these patterns of working offer a high degree of control over everyday life and perhaps even align work with some of the characteristics of "serious leisure". According to Stebbins (1982: 257), serious leisure involves a high degree of personal effort and special knowledge. It is not simply enjoyable but offers "self-actualization, self-enrichment, re-creation or renewal of self, feelings of accomplishment, enhancement of self-image, self-expression, social interaction and belongingness ...". Interestingly, one participant made this link himself. But caution is needed before regarding post-SPA paid work in this way. Some of the participants were explicit that their subjective well-being was enhanced through having an improved work-leisure balance (and choice over lifestyle) rather than work per se. With the UK government's planned delays to SPA, fewer older people will enjoy the option of working parttime whilst simultaneously drawing a state pension (protecting their income). Furthermore, older people are currently finding that opportunities to engage in stimulating, social non-work activities (particularly through informal adult education) are being restricted in the United Kingdom through redirections of central funds to younger people's training (McNair 2009). Thus the positive choices and health-promoting lifestyle patterns enjoyed by this sample of people aged 65 and over will not be so readily available in future years.

Follow-up studies are needed to explore how the accumulating adversities of old age (such as health problems, care-giving and bereavement) are addressed by people who have extended their working careers into their late 60s and beyond, and whether they have more or less 
International Journal of Ageing and Later Life

resilience to cope with such changes. It has been argued (at least in a leisure context) that older people may feel under pressure to adopt an "active ageing" lifestyle (Marhankova 2011) and questions arise in the current study as to whether eventual retirement (imposed perhaps by ill-health or caring responsibilities) might pose particular psychosocial challenges to older people who are committed to regarding later life as an opportunity for work and continuing development. Furthermore, a recent study of employers in four European countries found that only UK employers positively valued their older workers (Van Dalen et al. 2009). Whether the United Kingdom offers distinctive levels of support for older people to stay in employment or self-employment also needs further research, as contextual influences within the workplace were not explored.

This study located a group of highly motivated people for whom full retirement carried unwelcome connotations of passivity, decline, laziness and "cruising":

I think people have to feel valuable, otherwise they just spend their time playing golf and I really don't think it would be satisfying ... really, life is very short and you've really got to do something with it.

(Adam, 75, business consultant)

\section{Acknowledgement}

This study was completed as part of a project funded by the Institution of Occupational Safety and Health (UK).

\section{Corresponding Author}

Frances Reynolds, School of Health Sciences and Social Care, Mary Seacole Building, Brunel University, Kingston Lane, Uxbridge, Middlesex, UB8 3PH, UK. Email: Frances.Reynolds@brunel.ac.uk

\section{References}

Altschuler, J. (2004). Beyond money and survival: The meaning of paid work among older women. The International Journal of Aging and Human Development 58(3): 223-239. 
Aquino, J., Russell, D., Cutrona, C. \& Altmaier, E. (1996). Employment status, social support and life satisfaction among the elderly. Journal of Counseling Psychology 43(4): 480-489.

Barnes, H. \& Parry, J. (2004). Renegotiating identity and relationships: Men and women's adjustments to retirement. Ageing and Society 24(2): 213-233.

Barnes, H., Parry, J. \& Taylor, R. (2004). Working after State Pension Age: Qualitative Analysis. London: Department of Work and Pensions, Her Majesty's Stationery Office.

Braun, V. \& Clarke, V. (2006). Using thematic analysis in psychology. Qualitative Research in Psychology 3(2): 77-101.

Caplan, L. \& Schooler, C. (2003). The roles of fatalism, self-confidence, and intellectual resources in the disablement process in older adults. Psychology and Aging 18(3): 551-561.

Choi, N. (2001). Relationship between life satisfaction and postretirement employment among older women. International Journal of Aging and Human Development 52(1): 45-70.

Disney, R. \& Hawkes, D. (2003). Why has employment recently risen among older workers in Britain? In R. Dickens, P. Gregg \& J. Wadsworth (eds.), The Labour Market under New Labour: The State of Working Britain (pp. 53-69). Basingstoke, UK: Palgrave Macmillan.

Feldman, D. \& Kim, S. (2000). Bridge employment during retirement: A field study of individual and organizational experiences with postretirement employment. Human Resource Planning 23(1): 14-25.

Felstead, A. (2010). Closing the age gap? Age, skills and the experience of work in Great Britain. Ageing and Society 30(8): 1293-1314.

Harris, A. \& Thoresen, C. (2005). Volunteering is associated with delayed mortality in older people: Analysis of the longitudinal study of aging. Journal of Health Psychology 10(6): 739-752.

Henricksen, A. \& Stephens, C. (2010). An exploration of the happinessenhancing activities engaged in by older adults. Ageing International 35(4): 311-326.

Herzog, A., House, J. \& Morgan, J. (1991). Relation of work and retirement to health and well-being in older age. Psychology and Aging 6(2): 202-211.

Hill, R. (2006). Positive Aging. New York: W.W. Norton. 
International Journal of Ageing and Later Life

Hinterlong, J., Morrow-Howell, N. \& Rozario, P. (2007). Productive engagement and late life physical and mental health. Research on Aging 29(4): 348-70.

Hotopp, U. (2005). The employment rate of older workers. Office for National Statistics Labour Market Trends (February). Available on http:/ / www.ons.gov.uk/ons/search/index.html?pageSize $=50 \&$ sortBy $=$ none\& sortDirection $=$ none\&newquery $=$ manual + employment + older + workers (Accessed: July 25, 2012).

Howie, L. (2007). Health and well-being through occupation in later life. In S. Carmel, C. Morse \& F. Torres-Gil (eds.), Lessons on Aging From Three Nations, Volume I: The Art of Aging Well (pp. 19-28). Amityville, NY: Baywood.

Humphrey, A., Costigan, P., Pickering, K., Stratford, N. \& Barnes, M. (2003). Factors Affecting the Labour Market Participation of Older Workers. Research Report 200. Norwich, UK: Department for Work and Pensions, Her Majesty's Stationery Office. Available on http://193.129. 121.133/asd/asd5/rports2003-2004/rrep200.pdf (Accessed: July 25, 2012).

Keyes, C. \& Haidt, J. (2003). Introduction: Human flourishing - the study of that which makes life worthwhile. In C. Keyes \& J. Haidt (eds.), Flourishing: Positive psychology and the life well-lived (pp. 3-12). Washington, DC: American Psychological Association.

Komp, K., van Tilburg, T. \& Broese van Groenou, M. (2010). Paid work between age 60 and 70 years in Europe: A matter of socioeconomic status? International Journal of Ageing and Later Life 5(1): $45-76$.

Kooij, D., de Lange, A., Jansen, P. \& Dikkers, J. (2008). Older workers' motivation to continue to work: Five meanings of age: A conceptual review. Journal of Managerial Psychology 23(4): 364-394.

Lachman, M. (2006). Perceived control over aging related declines: Adaptive beliefs and behaviors. Current Directions in Psychological Science 15(6): 282-286.

Lampinen, P., Heikkinen, R., Kauppinen, M. \& Heikkinen, E. (2006). Activity as a predictor of mental well-being among older adults. Aging and Mental Health 10(5): 454-466. 
Luoh, M. \& Herzog, A. (2002). Individual consequences of volunteer and paid work in old age: Health and mortality. Journal of Health and Social Behavior 43(4): 490-509.

Marhankova, J. (2011). Leisure in old age - disciplinary practices surrounding the discourse of active ageing. International Journal of Ageing and Later Life 6(1): 5-32.

McNair, S. (2009). Demography and lifelong learning. Leicester: National Institute of Adult Continuing Education. Available on http://www.niace. org.uk/lifelonglearninginquiry/docs/Demography-Lifelong-Learning. pdf (Accessed: July 25, 2012).

Newson, R. \& Kemps, E. (2005). General lifestyle activities as a predictor of current cognition and cognitive change in older adults: A crosssectional and longitudinal examination. The Journals of Gerontology, Series B 60(3): 113-120.

Noonan, A. (2005). "At this point now": Older workers' reflections on their current employment experiences. The International Journal of Aging and Human Development 61(3): 211-241.

Office for National Statistics (2012). Older Workers in the Labour Market 2012. Available on http://www.ons.gov.uk/ons/rel/lmac/older-workersin-the-labour-market/2012/ older-workers-in-the-labour-market.html (Accessed: July 25, 2012).

Ozawa, M. \& Lum, T. (2005). Men who work at age 70 or older. Journal of Gerontological Social Work 45(4): 41-63.

Parry, J. \& Taylor, R. (2007). Orientation, opportunity and autonomy: Why people work after state pension age in three areas of England. Ageing and Society 27(4): 579-598.

Pensions Policy Institute (2011). Pension Facts December 2011. Available on http:/ / www.pensionspolicyinstitute.org.uk/default.asp?p=67 (Accessed: July 25, 2012).

Phillipson, C. \& Smith, A. (2005). Extending working life: A review of the research literature. Department for Work and Pensions Research report No. 299. Leeds: Department for Work and Pensions.

Reynolds, F. (2010). "Colour and communion": Exploring the influences of visual art-making as a leisure activity on older women's subjective well-being. Journal of Aging Studies 24(2): 135-143. 
International Journal of Ageing and Later Life

Scarmeas, N. \& Stern, Y. (2003). Cognitive reserve and lifestyle. Journal of Clinical and Experimental Neuropsychology 25(5): 625-633.

Shacklock, K., Brunetto, Y. \& Nelson, S. (2009). The different variables that affect older males' and females' intentions to continue working. Asia Pacific Journal of Human Resources 47(1): 79-101.

Smeaton, D. \& McKay, S. (2003). Working after State Pension Age: Quantitative Analysis. London: Department of Work and Pensions.

Smeaton, D., Vegeris, S. \& Sahin-Dikmen, M. (2009). Older Workers: Employment Preferences, Barriers and Solutions. Research Report 43. Manchester: Policy Studies Institute, Equality and Human Rights Commission. Available on http://www.equalityhumanrights.com/uploaded_ files/research/older_workers_employment_preferences_barriers_and_ solutions_v2.pdf (Accessed: April 11, 2012).

Smyer, M. A. \& Pitt-Catsouphes, M. (2007). The meanings of work for older workers. Generations 31(1): 23-30.

Stebbins, R. (1982). Serious leisure: A conceptual statement. The Pacific Sociological Review 25(2): 251-272.

Templer, A., Armstrong-Stassen, M. \& Cattaneo, J. (2010). Antecedents of older workers' motives for continuing to work. Career Development International 15(5): 479-500.

Van Dalen, H., Henkens, K. \& Schippers, J. (2009). Dealing with older workers in Europe: A comparative survey of employers' attitudes and actions. Journal of European Social Policy 19(1): 47-60.

Warr, P., Butcher, V., Robertson, I. \& Callinan, M. (2004). Older people's well-being as a function of employment, retirement, environmental characteristics and role preference. British Journal of Psychology 95(3): 297-324.

Westerhof, G. \& Tulle, E. (2007). Meanings of ageing and old age: Discursive contexts, social attitudes and personal identities. In J. Bond, S. Peace, F. Dittmann-Kohli \& G. Westerhof (eds.), Ageing in Society: European Perspectives on Gerontology (3rd ed., pp. 235-254). Thousand Oaks, CA: Sage. 